\title{
Anti Campylobacter Activity of Extracts of Daphne Mucronata and Symplocos Racemosa Against Avian Isolates
}

\author{
Saira Yahya ${ }^{*}$ and Shahana Urooj Kazmi \\ Department of Microbiology, University of Karachi, Karachi-75270, Pakistan.
}

\begin{abstract}
Bacterial gastroenteritis mainly caused by Campylobacter sp. is a major health concern in Pakistan. In order to investigate the primary sources of Campylobacter infection, total 81 cloacal swab samples were collected from different avian species in Karachi. Campylobacter strains were isolated, identified and antibiotic susceptibility pattern was studied. All isolates of Campylobacter were sensitive to Gentamicin and Ofloxacin. It was observed that $23 \%$ of the $C$. jejuni positive isolates were resilient to tetracycline, $45 \%$ to ampicillin, and $12 \%$ to erythromycin. The Campylobacter isolates showed susceptibility to the extracts of two plants namely Daphne Mucronata and Symplocos racemosa. The sensitivity of the isolates towards these extracts can be an alternative to the traditional antibiotics for the treatment of Campylobacter infections.
\end{abstract}

Keywords: Campylobacter, avian isolates, Daphne Mucronata, Symplocos racemosa.

doi.org/10.21089/njhs.21.0014

\section{INTRODUCTION}

Campylobacters are micro-aerophilic, curved, non-spore forming, gram-negative rods with a corkscrew motility. They are usually present in the intestinal tract of domestic and wild animals. Birds due to their body temperature serve as favorable host and provide suitable environment for Campylobacter [1-3]. An estimated $20-40 \%$ of sporadic disease might result from eating chicken $[4,5]$. The prevalence rates of Campylobacter sp. from broiler flocks are 38.1- 79.2\% in various European countries [6,7].

Campylobacters are the leading source of food-borne bacterial gastroenteritis in humans [8] and also a major public health concern in Pakistan. Campylobacter has been reported as the third most common pathogen in stool specimens [9]. They can create a momentary asymptomatic carrier state, as well as infection (diarrhea, enteritis, extra-intestinal infections and septicemia) in humans all around the world [2]. The common species involved in Campylobacter infections are C. coli, C. jejuni and C. lari.

Although most infections by Campylobacter sp. do not need antimicrobial treatment but it can be fatal in erythromycin are used generally to treat Campylobacter infections but the resistant Campylobacter strains are immunocompromised patients [10]. Fluoroquinolones and emerging with an alarming rate due to excessive use of antibiotic in the feed of chicken [11] resulting in an increased risk of death $[12,13]$.

*Address correspondence to this author at the Department of Microbiology, University of Karachi, Karachi-75270, Pakistan.

E-mail: saira.yahya@yahoo.com
With the emergence of resistant strains there is a dire need to find alternative to present drugs with high potency and reduced side effects [14]. Medicinal plants due to their excessive bioavailability provide a great alternative to find new lead molecule as an alternate and source of therapeutic agents for a very long time [15]. The plants chosen for this study, Daphne Mucronata and Symplocos recemosa, have no reported anti-Campylobacter activity although their antibacterial and antifungal properties towards few gram-positive and gram-negative organisms have been studied [16, 17].

This study was designed to isolate and characterize Campylobacter from the local poultry market of different areas from Karachi. The antibiotic resistance profile of Campylobacter strains was determined. Furthermore, the antimicrobial potential of the Butanolic extract, DM organic extract, Hexane fraction and water fraction of Symplocos recemosa and Daphne Mucronata against Campylobacter isolates was also determined. The existence of drug resistant Campylobacter poultry strains might draw some information on the spread of antibiotic resistance in human infections.

\section{MATERIALS AND METHODS}

\section{Sampling}

Cloacal swabs were collected from poultry retail shops as well as from the local avian market in Karachi, Pakistan. A total of 81 cloacal swabs were collected by using sterile cotton swabs. The swabs were transported to laboratory and processed for culture and Campylobacter isolation. 


\section{Culturing and Isolation}

The cloacal swab samples were enriched for 3-4 hours in thioglycollate enrichment broth (Oxoid) containing Campylobacter selective supplement (Oxoid) and then $100 \mu$ of the thioglycollate broth was inoculated on modified Campylobacter agar base medium with addition of 5\% sheep blood and Campylobacter selective supplement (Oxoid) to get suspected Campylobacter colonies. The agar plates were incubated at $42^{\circ} \mathrm{C}$ for $48-72$ hours in a microaerophilic environment $\left(10 \% \mathrm{CO}_{2}, 5 \% \mathrm{O}_{2}\right.$ and $\left.85 \% \mathrm{~N}_{2}\right)$ by using airtight jar (2.5 liters) containing CampyGen sachets (Oxoid). Suspected Campylobacter colonies were further sub-cultured on Muller Hinton Agar (Oxoid) with addition of 5\% sheep blood for characterization [18].

\section{Biochemical Identification}

The isolates showing characteristic Campylobacter growth on media plates and microscopic features were subjected to standard biochemical tests comprised of catalase, coagulase, oxidase, nitrate reduction, hippurate, $\mathrm{H}_{2} \mathrm{~S}$ production in TSI, growth at various incubation temperatures and in $3.5 \% \mathrm{NaCl}$ [19].

\section{Antibiotic Susceptibility Test}

Antimicrobial sensitivity pattern of the isolated Campylobacter isolates against antibiotics mentioned in Table $\mathbf{3}$, were determined by the Kirby-Bauer Disc diffusion method [20]. Inoculum was prepared from a 48 hour. grown culture. An inoculum containing $10^{8}$ cells were prepared in sterilized saline by matching the turbidity with $0.5 \mathrm{McFarland}$ turbidity standard. A uniform lawn was prepared using a sterile cotton swab. Discs of respective antibiotics were placed and plates were incubated for 24 hours. under microaerophilic conditions. A zone of inhibition with diameter $\leq 10 \mathrm{~mm}$ was considered as resistant, zone size between $10-13 \mathrm{~mm}$ as intermediate and $\geq 13 \mathrm{~mm}$ was considered breakpoint for susceptibility [21, 22].

\section{Extract Preparation}

The aqueous extracts (10\%) of Daphne murconata and Symplocos racemosa were prepared in distilled water by boiling the dried and chopped leaves for $\sim 5 \mathrm{~min}$. The aqueous extracts were sterilized by passing through $0.22 \mu \mathrm{m}$ membrane filters (Nalgen). Aliquots of $10 \mathrm{ml}$ were prepared and stored at $-20^{\circ} \mathrm{C}$ until use $[23,24]$.

The organic extracts were prepared by percolating the dried and chopped plant material at room temperature by macerating it in methanol. The methanol extracts were then dried out, dissolved in water and extracted with the desired solvents (hexane, butanol) [23, 24].

\section{Minimum Inhibitory Concentration (MIC) of Extracts}

The effect of the extracts of two medicinal plants, Daphne murconata and Symplocos racemosa was determined against the Campylobacter isolates. The MIC's of the extracts were determined by micro dilution method by using 96 well plate. Inoculum containing $10^{8}$ cells was prepared from 48 hours grown cells by matching with $0.5 \mathrm{McFarland}$ standard. Twofold serial dilutions of the plant extracts were prepared in Muller Hinton broth in the range of 7.81-250 $\mathrm{g} \mathrm{ml}^{-1}$ concentration. An inoculum of Campylobacter isolates containing $10^{6} \mathrm{CFU} \mathrm{m}{ }^{-1}$ cells were inoculated in each well. The controls used were Muller Hinton broth (negative control), test organism plus Muller Hinton broth (positive control) and the respective extract plus Muller Hinton broth (extract control). Minimum concentration of each extract that yielded no bacterial growth was considered as the MIC of that extract.

\section{Statistical Analysis}

All experiments were carried out in triplicate. The experimental means and standard deviations were calculated using MS Excel 2013.

\section{RESULTS AND DISCUSSIONS}

Campylobacter species are one of the prominent causes of gastrointestinal infections globally [28]. Over the last decade, the incidence of Campylobacter associated food poisoning has gradually increased and it is now reported to be the leading cause of bacterial gastroenteritis in the developing countries. Several studies have shown that poultry, in particular chicken, is the main source of Campylobacter and its meat is principally related to Campylobacter infection in humans $[25,26]$.

Present study demonstrated the significance of chickens, parrots and sparrows as reservoirs of Campylobacter species. On the basis of biochemical tests, Campylobacter species were characterized into two groups i.e. C. jejuni positive or negative, since $C$. jejuni is the most common gastroenteritis caused by Campylobacter specie. Characterization of the Campylobacter species is routinely done on the basis of incubation temperature of $42^{\circ} \mathrm{C}$ to inhibit the growth of other non-thermophilic Campylobacter species and hippurate test [20]. Additionally, some Campylobacter species, e.g., C. rectus, C. curvus, C. concisus, $C$. showae and C. gracilis need to be incubated in a hydrogen-supplemented microaerophilic atmosphere for isolation [27].

The results indicate that out of 81 cloacal avian samples, 51 (62\%) were positive for $C$. jejuni strains. Among them 30 $(60 \%)$ were isolated from the cloacal swabs of chickens, 16 (32\%) from parrots and $5(10 \%)$ from sparrows (Table $\mathbf{1}$ and 2). This indicates the high prevalence of $C$. jejuni in different avian species as demonstrated by earlier studies [28, 29]. 
Table 1. Phenotypic identification tests for the determination of Campylobacter species.

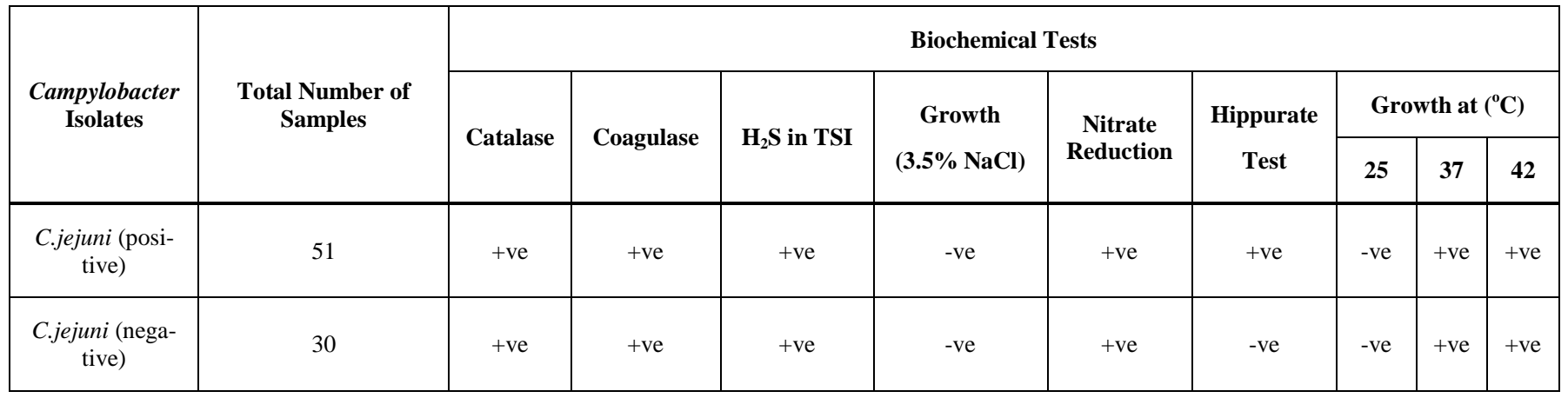

Table 2. Distribution of Campylobacter isolates among avian species.

\begin{tabular}{|c|c|c|c|}
\hline Avian Species & Total no of Samples & C. jejuni (Positive) & C. jejuni (Negative) \\
\hline Chickens & 45 & 30 & 15 \\
\hline Parrots & 27 & 16 & 11 \\
\hline Sparrows & 09 & 05 & 04 \\
\hline
\end{tabular}

Table 3. Antibiotics used against Campylobacter isolates.

\begin{tabular}{|c|c|}
\hline Antibiotics & Concentration $(\mu \mathrm{g} / \mathbf{m l})$ \\
\hline Ampicillin & 25 \\
\hline Cephalothin & 30 \\
\hline Erythromycin & 15 \\
\hline Gentamycin & 10 \\
\hline Ofloxacin & 5 \\
\hline Tetracycline & 30 \\
\hline Nalidixic acid & 30 \\
\hline
\end{tabular}

Epidemiology of Campylobacter-associated infections appear to differ between developed and developing countries. In the developed world, both chicken and adults are at risk of Campylobacter infection. Transmission of the bacterium has been connected to ingestion of unpasteurized milk, undercooked meat, contaminated water and travel to Campylobacter endemic areas [1, 3]. In contrast, in the developing world it is endemic and the infection is generally found in children, signifying that protective immunity is developed in early life due to its high level exposure [30-32].

Antibiotics not only play a pivotal role in the treatment and prevention of human and veterinary infections, they are also used in animal feed as growth promoters [33]. The increased use of antibiotics has resulted in augmented occurrence of enteric bacterial infections along with increased antibiotic resistance [34]. According to the antibiotic resistance profile observed in this study, $C$. jejuni were found to be resistant against commonly used antibiotics; Erythromycin (12\%), Cephalothin (100\%), Tetracylcline (23\%) and Ampicillin $(45 \%)$ as shown in (Fig. 1). On the other hand, C. jejuni isolates were sensitive to Gentamycin, Ofloxacin and Nalidixic acid (Fig. 1).

Although Campylobacters are naturally susceptible to Fluroquinolines (ofloxacin, nalidixic acid), the resistance to these 


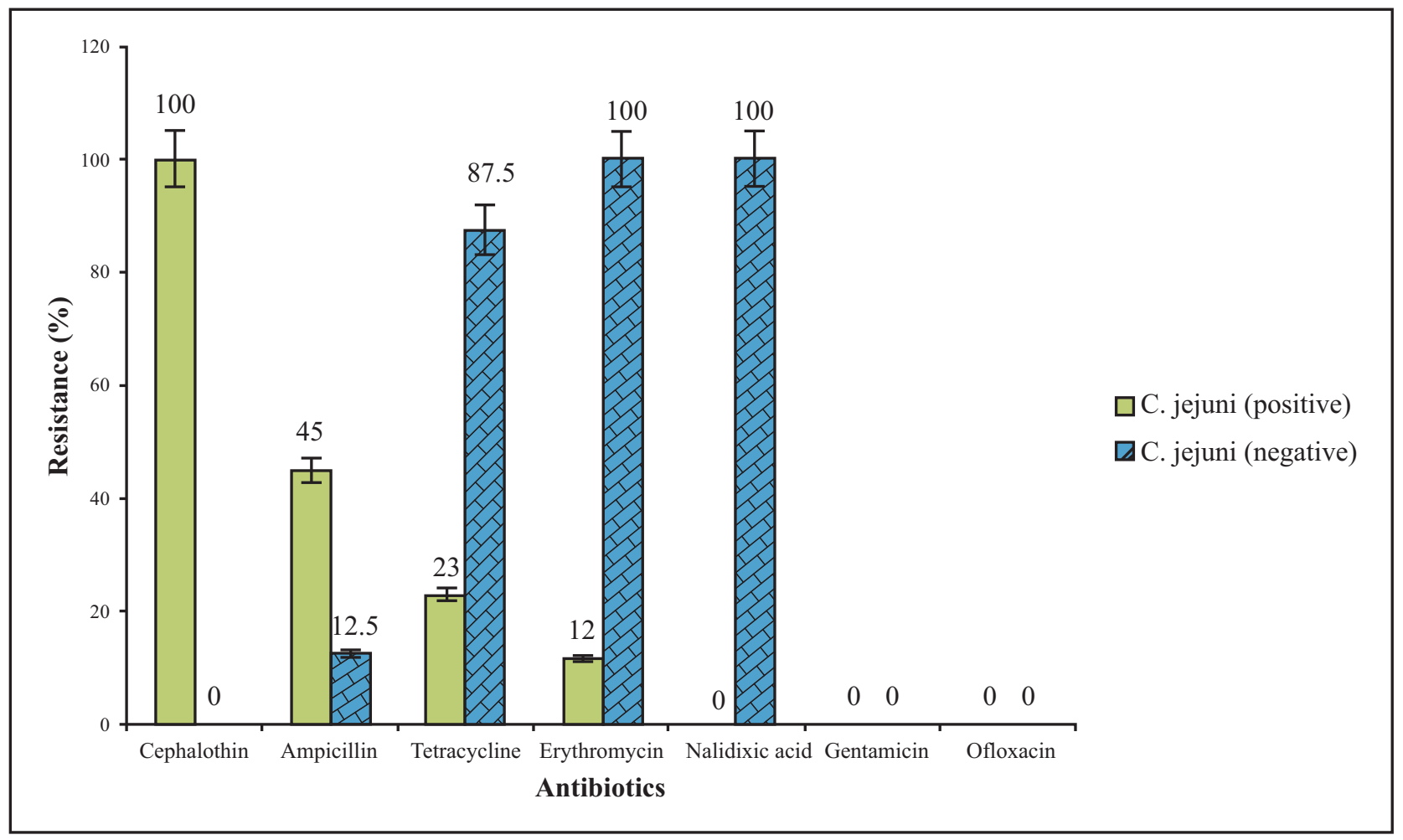

Fig (1). Antibiotic resistance profile of the Campylobacter isolates.

antimicrobials has amplified during the 1990s [9, 35, 36]. Increasing antimicrobial resistance has complicated the empirical treatment of Camypylobacter infections in countries where fluoroquinolone-resistant strains predominate.

A number of drugs are still effective against the flouroquinolone-resistant Campylobacter strains such as erythromycin (a macrolide), but higher macrolide resistance rates have been reported in some countries. According to a survey, the rate of erythromycin resistance among $C$. jejuni was $17 \%$ in both Spain and Taiwan [37, 38]. Nalidixic acid resistant mutants of $C$. jejuni and $C$. coli showed cross resistance in a study [39]. Due to high prevalence of ampicillin-resistant Campylobacter species, ampicillin is not a drug of choice for Campylobacteriosis treatment. Tetracycline and gentamicin are recommended as alternative treatments, but they are also widely used both therapeutically and sub therapeutically as feed additive for livestock and poultry [40].

To handle antimicrobial resistant pathogen there is a dire need to find new alternative chemical entity with antibacterial action and less toxicity toward body cells. Plants provide great alternative to find new lead molecules in terms of their secondary metabolites and bioavailability. Medicinal plants were used as therapeutic agents and as a result a large number of drugs have been discovered on the basis of traditional use of medicinal plants $[15,41]$. The plant-based system of infection control and treatment is still continued in the de- veloping countries. According to a WHO report, approximately $80 \%$ of the world population relies on traditional medication for their primary health care [42]. Several studies showed the anti-microbial potentials of fruits, vegetables and plant oils which can be an alternate source for the development of new, better and non-toxic drugs [43, 44]. Moreover, different fractions extracted from plants can safely be used in tropical formulations for treating the cutaneous infections as there are no reports of harmful effects found. The natural extracts used in this study for the determination of MICs extracted from Daphne Mucronata and Symplocos recemosa have been commonly used for treating all kinds of inflammation by the local people in Northern areas of Pakistan and India $[45,46]$.

This work was focused on the Butanolic extract, DM organic extract, Hexane fraction and water fraction of Symplocos recemosa and Daphne Mucronata. The MICs were found to be in the range of $15.625-125 \mu \mathrm{g} / \mathrm{ml}$. Butanolic extract was found to be more potent among all extracts against the Campylobacter isolates (Table 4). The results strengthened the evidence of antibacterial potential of these plants [18, 17]. These variations in the antibacterial activity of the plant extracts in different solvents is dependent on the different chemical nature of the solvents $[26,36]$.

The results strongly suggest that these components are potential candidates for the development of new, better and 
safer alternative anti-bacterial drugs that can effectively be used for the treatment of patients suffering from diseases caused by potential human pathogens like $C$. jejuni.

Table 4: Comparison of susceptibilities of Campylobacter isolates to the extracts of Daphne murconata and Symplocos racemosa.

\begin{tabular}{|c|c|c|c|c|}
\hline \multirow{2}{*}{ Campylobacter Isolates } & \multicolumn{4}{|c|}{ MIC ( $\boldsymbol{\mu g} / \mathbf{m l})$} \\
\cline { 2 - 5 } & Water Extract & Hexane Extract & n-Butanol Extract & DM organic Extract \\
\hline C. jejuni (positive) & $31.25 \pm 0.11$ & $31.25 \pm 0.09$ & $15.625 \pm 0.10$ & $62.5 \pm 0.12$ \\
\hline C. jejuni (negative) & $15.625 \pm 0.15$ & $125 \pm 0.06$ & $15.625 \pm 0.09$ & $125 \pm 0.11$ \\
\hline
\end{tabular}

\section{CONCLUSION}

Bioactivity of the plant extracts not only provides a scientific basis for its use in traditional health care system but also suggests that these extracts or their bioactive components, if found non-toxic in animal studies and clinical trials, can serve as an effective alternative source for developing new antibiotics for the treatment of Campylobacter infections.

\section{ACKNOWLEDGEMENT}

Declared None.

\section{CONFLICT OF INTEREST}

Declared None.

\section{REFERENCES}

[1] Butzler PJ. Campylobacter, from obscurity to celebrity. Clin. Microbiol. Infect. 2004; 10: 868-876.

[2] Friedman CR, Neimann J, Wegener, HC, Tauxe RV. Epidemiology of Campylobacter jejuni infections in the United States and other industrialized nations. in Campylobacter. 2 edn, vol. II/6, ASM International, Washington, USA, pp. 121-138. 2000.

[3] Hussain I, Mahmood MS, Akhtar M, Khan A. Prevalence of Campylobacter species in meat, milk and other food commodities in Pakistan. Food Microbiol,. 2007; 24: 219-222.

[4] Nadeau E, Messier S, Quessy S. Prevalance and comparison of genetic profiles of Campylobacter strains isolated from poultry and sporadic cases of Campylobacteriosis in humans. J. Food Prot., 2002; 65(1): 73-78.

[5] Vellinga A, Van Loock F. The dioxin crisis as experiment to determine poultry-related Campylobacter enteritis. Emerg. Infect. Dis., 2002; 8(1): 19-22.

[6] Lawes J, Vidal A, Clifton-Hadley F, Sayers R, Rodgers J, Snow L, Evans SJ, Powell LF. Investigation of prevalence and risk factors for Campylobacter in broiler flocks at slaughter: results from a UK survey. Epidemiol Infect., 2012; 140: 1725-37.

[7] Torralbo A, Borge C, Allepuz A, García-Bocanegra I, Sheppard S, Perea A, Carbonero A. Prevalence and risk factors of Campylobacter infection in broiler flocks from southern Spain. Prevent Veter Med., 2014; 114: 106-113.
[8] Moore JE, Corcoran D, Dooley JS, Fanning S, Lucey B, Matsuda M, McDowell DA, Mégraud, F, Millar BC, O'Mahony R, O'Riordan L, O'Rourke M, Rao JR, Rooney PJ, Sails A, Whyte P. Campylobacter. Vet Res. 2005; 36(3): 351-382.

[9] Ibrahim NG, Zafar A, Hasan R. Evaluation of frequency of isolation and trends in antibiotic resistance among Campylobacter isolates over 11-year period. J. Pak. Medical. Assoc., 2004; 54: 291-294.

[10] Norrby SR. Principles of chemoprophylaxis. In: Finch RG, et al., eds. Antibiotic and chemotherapy, $8^{\text {th }}$ ed. New York, Elsevier Science., 2003; 120-122.

[11] Nachamkin I, Ung H, Ming I. Increasing fluoroquinolone resistance in Campylobacter jejuni, Pennsylvania, USA, 1982-2001. Emerg. Infect. Dis., 2002; 8: 1501-1503.

[12] Engberg J. Quinolone-resistant Campylobacter infections: risk factors and clinical consequences. Emerg. Infect. Dis., 2004; 10: 1056-1063.

[13] Nelson JM Smith KE, Vugia DJ, Rabatsky-Ehr T, Segler SD, Kassenborg HD, Zansky SM, Joyce K, Marano N, Hoekstra RM, Angulo FJ. Prolonged diarrhea due to ciprofloxacin resistant Campylobacter infection. J. Infect. Dis., 2004; 190(6): 1150-1177.

[14] O'Gara EA, Hill DJ, Maslin DJ. Activities of garlic oil, garlic powder, and their diallyl constituents against Helicobacter pylori. App. Environ. Microbiol., 2000; 66: 2269-2273.

[15] Newman DJ, Cragg GM, Snader KM. The influence of natura products upon drug discovery. Nat. Prod. Rep., 2000; 17: 215-234.

[16] Javidnia K, Miri R, Naafi RB, Jahromi NK. A preliminary study of the biological activity of Daphne Mucronata royle. DARU J. Pharma. Sci., 2003; 11(1): 28-31.

[17] Devmurari VP. Antibacterial evaluation and phytochemical screening of Symplocos Racemosa Roxb. Int J PharmTech Res 2010; 2(2): 1359-1363.

[18] Aydon F, Atabay HI, Akan, M. The isolation and characterization of Campylobacter jejuni subsp. jejuni from domestic geese. J. Appl. Microbiol., 2000; 90: 637-642.

[19] Harvey SM. Hippurate hydrolysis by Campylobacter fetus. J. Clin Microbiol., 1980; 11: 435-37.

[20] Bauer AW, Kirby WMM, Sherris JC, Turck M. Antibiotic susceptibility testing by a standardized single disk method. Am. $J$. Clin. Pathol., 1966; 36: 493-496.

[21] Ge B, Bodeis S, Walker RD, White DG, Zhao S, McDermott PF, Meng J. Comparison of the E test and agar dilution method for in 
vitro antimicrobial susceptibility testing of Campylobacter. J. Antimicrob Chemother., 2002; 50: 487-494.

[22] Luber P, Bartelt E, Genschow E, Wagner J, Hahn H. Comparison of broth microdilution, E test, and agar dilution methods for antibiotic susceptibility testing of Campylobacter jejuni and Campylobacter coli. J. Clin. Microbiol., 2003; 41: 1062-1068.

[23] Qaralleh H, Abboud MM, Khleifat KM, Tarawneh KA, ALThunibat OY. Antibacterial activity in vitro of Thymus capitatus from Jordan. Pak. J. Pharm. Sci., 2009; 22(3): 247-251.

[24] Shafique S, Shafique S, Bajwa R, Akhtar N, Hanif S. Fungitoxic activity of aqueous and organic solvent extracts of Tagetes erectus on phytopathogenis fungus- Ascochyta rabiei. Pak. J. Bot., 2011; 43(1): 59-64.

[25] Harris NV, Thompson D, Martin DC, Nolan CM. Survey of Campylobacter and other bacterial contaminants of pre-market chicken and retail poultry and meats, King County, Washington. Am. J. Public Health., 1986; 76(4): 401-406.

[26] Humphrey TJ, Henley A, Lanning DG. The colonization of broiler chickens with Campylobacter jejuni: some epidemiological investigations. Epidemiol. Infec., 1993; 110: 601-607.

[27] Mentzing LO. Waterborne outbreaks of Campylobacter enteritis in central Sweden. Lancet. 1981; 2(8242): 352-354.

[28] Ejaz S, Aslam U, Lim CW. A note on the prevalence of Campylobacters in chicken flocks in Pakistan. J. Animal. Feed Sci., 2004; 13: 323-327.

[29] Irfan S, Ahmad A, Guhar D, Khan E, Malik F, Mahmood S, Zafar A. Fluoroquinolone and macrolide co-resistance in clinical isolates of Campylobacter species: a 15-year study in Karachi, Pakistan. J. East. Mediter. Health, 2010; 16(12): 1226-1230.

[30] Blaser MJ. Epidemiological and clinical features of Campylobacter jejuni infections. J. Infect. Dis., 1997; 176: 103-105.

[31] Calva JJ, Ruiz-Palacios GM, Lopez-Vidal AB, Ramos A, Bojalil R. Cohort study of intestinal infection with Campylobacter in Mexican children. Lancet. 1988; 1(8584): 503-506.

[32] Georges-Courbot MC, Cassel-Beraud AM, Gouandjika I, Monges J, Georges AJ. A cohort study of enteric Campylobacter infection in children from birth to two years in Bangui (Central African Republic). Trans. R. Soc. Trp. Med. Hyg., 1990; 84(1): 122-125.

[33] Maron D, Smith T, Nachman K. Restrictions on antimicrobial use in food animal production: an international regulatory and economic survey. Globaliz Health., 2013; 9:48.

[34] Houndt T, Ochman H. Long-term shifts in patterns of antibiotic resistance in enteric bacteria. Appl. Environ. Microbiol., 2011; 66:5406-5409.
[35] Hakane A, Jousimies-Somer H, Siitonen A, Huovinen P, Kotilainen P. Fluoroquinolone resistance in Campylobacter jejuni isolates in travelers returning to Finland. Association of ciprofloxacin resistance is prevalent. Emerg. Infect. Dis. 2003; 9(2): 267-270.

[36] Payot S, Bolla JM, Corcoran D, Fanning S, Megraud F, Zhang Q Mechanisms of fluoroquinolone and macrolide resistance in Campylobacter spp. Microbes. Infect., 2006; 8: 1967-1971.

[37] Li CC, Chiu CH, Wu JL, Huang YC, Lin TY. Antimicrobial susceptibilities of Campylobacter jejuni and coli by using E-test in Taiwan. Scand J. Infect. Dis., 1998; 30(1): 39-42.

[38] Sáenz Y, Zarazaga M, Lantero M, Gastanares MJ, Baquero F, Torres C. Antibiotic resistance in Campylobacter strains isolated from animals, foods, and humans in Spain in 1997-1998. Antimicrob Agents Chemother., 2000; 44(2):267-71.

[39] Taylor DE, Ng LK, Lior H. Susceptibility of Campylobacter species to Nalidixic acid, Enoxacin, and other DNA Gyrase Inhibitors. Antimicrob agents Chemother., 1985; 28(5): 708-710.

[40] Trieber CA, Taylor DE. Mechanisms of antibiotic resistance in Campylobacter. pp. 441-454. In I. Nachamkin and M. J. Blaser (ed.), Campylobacter, $2^{\text {nd }}$ ed. American Society for Microbiology, Washington, D.C. 2000

[41] Shu YZ. Recent natural product based drug development: a pharmaceutical industry perspective. J. Nat. Prod., 1998; 61(8): 1053-1071

[42] Farnsworth NR, Akerele O, Bingel AS, Soejarto DD, Guo Z Medicinal plants in therapy. Bulletin of the World Health Organization. 1985; 63: 965-981.

[43] Majhenic L, Kerget MS, Knez Z. Antioxidant and antimicrobial activity of guarana seed extracts. Food Chemistry, 2007; 104: 12581268.

[44] Parekh J, Jadeja D, Chanda S. Efficacy of aqueous and methanol extracts of some medicinal plants for potential antibacterial activity. Turk. J. Bio., 2005; 29: 203-210.

[45] Kalidass C. Distribution and population status of a critically endangered tree species Symplocos racemosa Roxb. in Eastern Ghats of Odisha. Int. J. Adv. Res., 2014; 2(11): 27-32.

[46] Zaidi A, Bukhari SM, Khan FA, Noor T, Iqbal N. Ethnobotanical, Phytochemical and Pharmacological Aspects of Daphne Mucronata (Thymeleaceae). Trop. J. Pharma. Res., 2015; 14(8): 1517-1523.

(C) 2017 National journal of health sciences.

This is an open-access article. 